Original Research Paper

\title{
Effect of Novel Thermo-Chemical Treatment on Bending Strength of Laminated Glass
}

\author{
${ }^{1,2}$ Ajitanshu Vedrtnam \\ ${ }^{I}$ Department of Applied Mechanics, \\ Motilal Nehru National Institute of Technology Allahabad, Allahabad, UP, India-211004 \\ ${ }^{2}$ Department of Mechanical Engineering, Invertis University, Bareilly, UP, India-243001
}

Article history

Received: 11-01-2018

Revised: 07-03-2018

Accepted: 26-03-2018

Corresponding Author:

Ajitanshu Vedrtnam

Department of Applied Mechanics,

Motilal Nehru National Institute of

Technology Allahabad, Allahabad,

UP, India-211004, India

Email: ajitanshu.m@invertis.org

\begin{abstract}
The science of thermal and chemical treatment of glass is well documented. The Laminated Glass (LG) is usually not treated as either treated glass is used during production or lower melting temperature of interlayer does not allow the treatment. The present work reports the novel methods of thermo-chemical treatment of LG having annealed soda lime glass plies. Five thermo-chemical treatments were performed on LG using different salts (Potassium Nitrate Carbohydrazide, Lithium Nitride), via clay coating (saturated with salts), using fused silica wafer coated with a thin graphene layer and utilizing the microwave heating. The bending strength is measured before and after thermo-chemical treatment using Q-set coupled bending tester (following the ASTM D790-03). The linear elastic model is utilized for obtaining normal stress and deformation at fracture load using ANSYS 14.5. The bending strength of thermo-chemical treated LG sample was found significantly higher than untreated LG in the most cases. The fracture pattern of the treated LG was also modified compared to the untreated LG as impurities and defects were reduced during treatment. The mechanics of increased bending strength and modified fracture is also discussed with reference to the effects of thermo-chemical treatment of LG, however, the need of a specialized numerical method that can effectively model the implications of treatment on LG and multiple fractures experienced by the LG during testing are suggested as future work.
\end{abstract}

Keywords: Bending Strength, Thermo-Chemical Treatment, Laminated Glass, Polyvinyl Butyral, FEM

\section{Introduction}

The higher strength and designed fracture pattern will enhance capabilities of LG as protective glass in automotive and structural applications. The thermal treatment includes heating the glass above its transition temperature $\left(564\right.$ to $\left.620^{\circ} \mathrm{C}\right)$ followed by rapid cooling by forced air drafts. The chemical treatment includes the exchange of sodium ion with potassium ions from the glass surface. The new ways of thermal treatment are attempted and reported (U.S. Patent Number 5882370; 5743931; 5858047; 5022908; 5352263; 5079931; 5078774; 5059233; 5066320; 5057138) using tunnel type furnaces. Most of them have reported an incremental heating inside tunnel while glass is moving on the conveyor or similar arrangements. However, such an arrangement suffers from a consequence that the temperature of the upper side and lower side of the glass has different temperature either due to rollers, support mechanism or otherwise (US Patent Number 6408649). That results in deterioration of the surface and optical quality of the glass. Additionally, the major problem with many of the thermal treatment method results due to increasing the heating rate to be kept lower from room temperature to the softening temperature or else cracking can occur; the different temperature at different zones in the glass may also result cracking due to internal thermal stresses in the glass. The localized heating methods were also tried (U.S. Patent Number 5591245; 5755845) with an aid of expensive modification in the furnaces. The attempts were made to keep the size of furnace smaller by creating separate chamber inside the furnace or transferring glass to different section as the temperature of the glass reaches to $450^{\circ} \mathrm{C}$. The glass was heated after 450 to $900^{\circ} \mathrm{C}$ (U.S. Patent Number 5232482 ) or $1000^{\circ} \mathrm{C}$ (U.S. Patent Number 5306324) using powerful electric 
or gas heater; microwave energy was also utilized (U.S. Patent Number 4838915 ; 5656053) for heating of glass after $420-450^{\circ} \mathrm{C}$. To overcome the problem of nonuniform heating with an objective of keeping heating time and furnace length short attempts were made by combining hot air and infrared heating (U.S. Patent Number 5368624) designed heating devices (U.S. Patent Number 6005230) and using roller heat in furnace (U.S. Patent Number 4591374). Still, there is a need for a method that can reduce the heating time and length of the furnace but ensure rapid heating at contracted, localized places on the glass. The microwave heaters were also proposed to achieve the stated objective (U.S. Patent Number 5828042), however, without changing the properties of glass reducing temperature differential throughout the thickness of the glass is challenging. The tempering method considered qualified if the surface compressive strength of glass exceeds $100 \mathrm{MPa}$; higher surface compressive stress results-in smaller glass particles when fractured by reducing microscopic surface cracks and putting resistance to the propagation of cracks. The reason why surface compressive stress increases can be understood by Fig. 1; The surface cools first during air quenching, hotter molten glass at core once solidify put surfaces in compression and core in tension. The analysis of the thermal tempering process for different application of glasses is discussed in (Zhang et al., 2014; Shao et al., 2014; Koike et al., 2012; Loch and Krause, 2002; Soules et al., 1987; Aben and Guillermet, 1993; Kuske and Robertson, 1974; Shepard et al., 2003; Brodland and Dolovich, 2000; Moynihan et al., 1976; Narayanaswamy, 1971; Tool, 1976; Narayanaswamy, 1978; Nielsen et al., 2010; ABAQUS, 2002; Arrazola and Özel, 2010; Bao-Wei et al., 2016a; Deng and Murakawa, 2006). The effect of tempering of glass is discussed during blast condition (Zhang et al., 2014), fire condition (Shao et al., 2014) and on the hardness (Koike et al., 2012). The numerical modelling for stress and structural relaxation is discussed in (Koike et al., 2012; Soules et al., 1987; Shepard et al., 2003; Brodland and Dolovich, 2000; Moynihan et al., 1976; Narayanaswamy, 1971; Tool, 1976; Narayanaswamy, 1978; Nielsen et al., 2010; ABAQUS, 2002).

The chemical strengthening of alkali-containing glass is routed via an ion-exchange process in which small ions (sodium) are replaced with larger ions (Potassium) putting surface of the glass in compression and core at tension. Fig. 2 demonstrates the process of chemical tempering of glass and resulting SEM micrographs \& fracture pattern. The chemical tempering results in higher compression at surface thus larger strengthening, compression depth is smaller, better optical quality, but costlier than conventional thermal tempering. The analysis of the chemical tempering process for different application of glasses is discussed in (Arrazola and Özel, 2010; Bao-Wei et al., 2016a; Deng and Murakawa, 2006; Boubakera et al., 2014; Bao-Wei et al., 2016b; Varshneya and Kreski, 2012; Mazzoldi et al., 2013;
Green, 2008; Varshneya, 2010a; Karlsson et al., 2010; Gy, 2008; Varshneya, 2010b; 2016; Xiangchen et al., 1986; Araujo et al., 2003; Fu and Mauro, 2013; Sglavo et al., 2014; Sglavo, 2015; Varshneya and Spinelli, 2009; Saunders and Kubichan, 1969; Shelestak et al., 2005). The structure-property relationship depends on each network former and modifier, chemical composition along with the thermal history of glass (Kolitsch and Richter, 1980; Hevesy, 1928; Frischat, 1975; Cormier et al., 2000; Du and Stebbins, 2005; Wu and Stebbins, 2010; Zheng et al., 2012a). Thus, the surface modification and fracture design are the functions of structure-property relationship and efforts are made for numerical modeling of structure-property relationship with the help of topological constraint theory (Zheng et al., 2012b; Smedskjaer et al., 2013; Wu and Stebbins, 2013; Smedskjaer et al., 2010a). However, there is no universal model available to predict bounding preferences and bound energy parameters for obtaining desired fracture pattern of glass. The structural origins of an alkali and the alkaline earth effects in glasses (Smedskjaer et al., 2010b; 2011; Mauro, 2011), the optimum potential energy functions explaining interatomic bonding (Maass, 1998; Greaves, 1998), atomic scale simulation to predict structure-property relationship and thermal histories and controlling nucleation and crystal growth through the glass chemistry are few unanswered questions that can help in devising the method for surface and fracture pattern modification of glass and LG.

The LG can't be treated by usual thermal or chemical treatment methods or not even treated generally due to the melting temperature of the interlayer is quite low and treatment of the glass can be performed before the lamination process. But the challenges like, LG treatment during operating conditions to increase the life of LG component, fracture pattern modification to improve the post breakage response of $L G$ and strengthening LG for making it better protective material for defence, structural and automotive applications generates the requirement of treatment of LG. The treatment of LG during operating condition is the requirement of the day. In this direction, very few authors have reported significant contributions. Li et al. (2013) have reported the effect of etching on the glass surface using hydrofluoric acid for organic-inorganic LG with Polyurethane (PU) as an adhesive interlayer. It was found that acidic etching treatment for half-an-hour increases the bounding strength and fracture stress without affecting transparency or haze (Li et al., 2013). Alhazov and Zussman have reported the use of carbon nanotube embedded with polymer interlayer for increasing the impact strength; impact strength was increased but the transparency of LG was decreased (Alhazov and Zussman, 2012). Tsujioka et al. (2012) have used sol-gel transition silicate gel for the treatment of glass fabric in laminate and found significant improvement in fracture toughness and fracture pattern. 

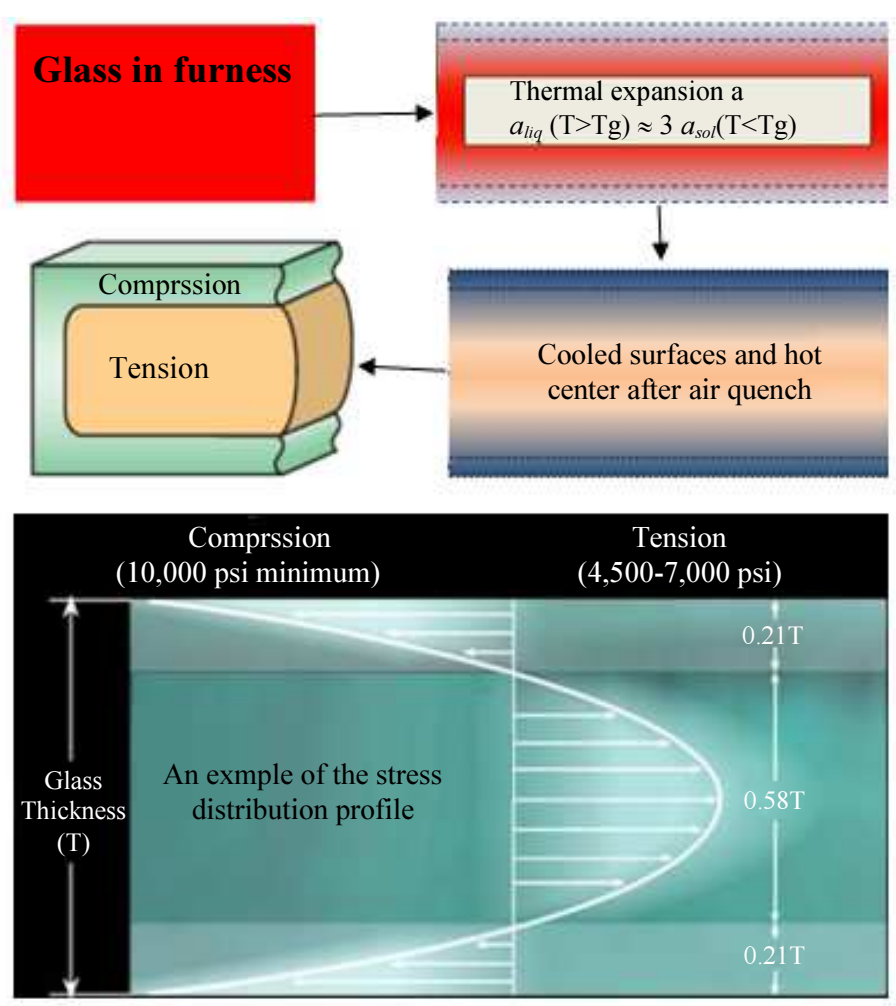

Fig. 1: Process of thermal tempering of glass

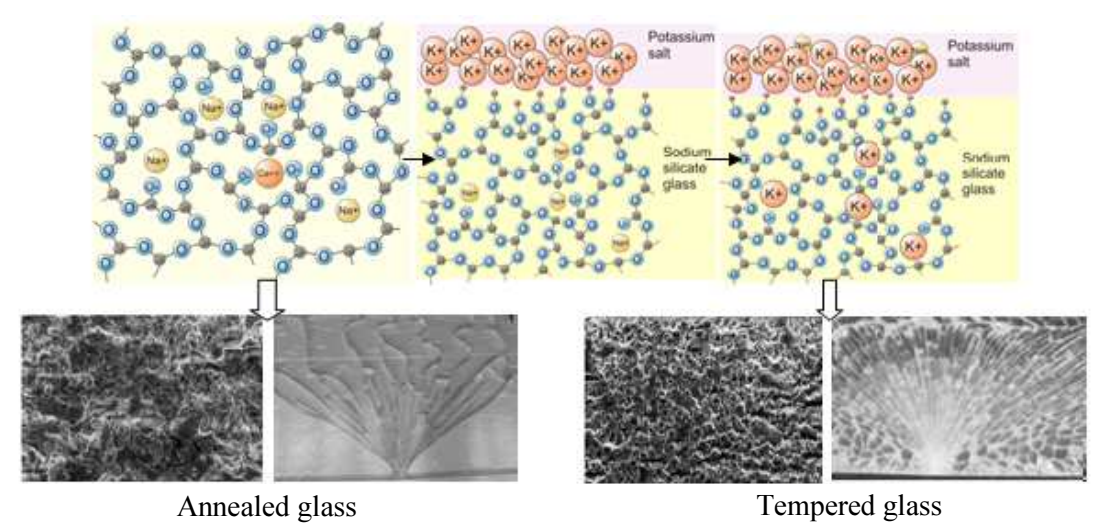

Fig. 2: Chemical tempering of glass and resulting SEM micrographs and fracture pattern

Based on the literature review, the methods of surface treatment produced favourable results were examined. The microwave baking (applied successfully for treatment of glass by number of cited authors), dipcoating of LG with sol-gel (most popular method for coating with some customization required for $\mathrm{LG}$ coating), clay coating (clay with salts was applied on LG before thermal treatment to avoid the effect of moisture on interlayer and better possible absorption of salts by LG surface) and dip coating with localized rapid heating method of LG (following successful application of this method in the cited literature for glass ) was performed and the bending strength of three LG samples of each type was evaluated. The treatment method would have an added advantage if that can be employed in operating LG component to encounter sub-critical growth of cracks during aging, the roughness of the edges during operation, the stress corrosion and the stress concentration. The description of LG and fracture of LG is discussed in (Vedrtnam and Pawar, 2017a; 2013; 2017b; 2017c; Sharma et al., 2017; Vedrtnam and Pawar, 2017d). The mechanical properties of the LG are often determined by bending tests (along with impact and blast performance), due to its significance in 
structural and other applications of LG (Vedrtnam and Pawar, 2017a; 2013; 2017b; 2017c; Sharma et al., 2017; Vedrtnam and Pawar, 2017d; 2018; 2017e; Vedrtnam, 2018; Hooper, 1973; Behr et al., 1993; Edel, 1997; Norville et al., 1998; Asik and Tezcan, 2005; Serafinaviciusa et al., 2013; Louter et al., 2012; Belis et al., 2009; Seshadri et al., 2002; Biolzi et al., 2010; Ivanov, 2006; Shelton and Mauro, 2010; Calderone et al., 2009; Serafinavičius et al., 2013; Galuppi and Carfagni, 2014; Pickett et al., 2004). The LG samples with $5 \mathrm{~mm}$ thick glass plates with an interlayer of PVB of $1.52 \mathrm{~mm}$ thickness were prepared using the autoclave. The LG samples were treated before evaluating the bending strength using Q-set coupled bending tester following the ASTM D790-03 (ASTM C158 or C1499 or ISO 1288 may also be used). FE simulation of experimentation is performed using the linear elastic model of ANSYS 14.5 software module. The results of simulation and experimentation were compared.

\section{Materials and Methods}

The LG samples were prepared by combining two annealed glass beams of thickness $5 \mathrm{~mm}$ each with an inter-layer (PVB) of $1.52 \mathrm{~mm}$ thicknesses in between. The chemical composition (wt. \%) of the glass used for experimentation includes $\mathrm{SiO}_{2} 74, \mathrm{Na}_{2} \mathrm{O} 13 \%, \mathrm{CaO}$ $10.5 \%, \mathrm{MgO} 0.2 \%, \mathrm{Al}_{2} \mathrm{O}_{3} 1.3 \%, \mathrm{~K}_{2} \mathrm{O} 0.3 \%$, SO3 0.2\%, $\mathrm{Fe} 2 \mathrm{O} 30.04 \%$ and $\mathrm{TiO} 20.01$. The glass transition temperature of the glasses used in the experimentation is between $570-580^{\circ} \mathrm{C}$.

The surface treatment of LG was performed using the combination of different methods: chemical etching, thin coating technique, cladding, microwave baking, dipcoating of glass with sol-gel, dip coating with localized heating and dip coating with microwave baking. However, the major constraint during LG treatment was the temperature of PVB interlayer should be lower than $140^{\circ} \mathrm{C}$ or if the higher temperature is considered for treatment then the melted/ jelly formed inter-layer should not flow so the methods were modified accordingly. The compressive stress of the glass surface was evaluated using strain scope.

The first method used for the LG treatment includes preparation of a mixture of Potassium Nitrate $(5 \mathrm{gm})$ and Carbohydrazide $(2.5 \mathrm{gm})$ with $150 \mathrm{ml}$. water. The mixture was prepared at room temperature using the stirrer (120 RPM for $20 \mathrm{~min}$ ); once the powders were fully dissolved in water the LG sample was dipped into the solution (LG sample was sealed off at the edges before dipping in the solution). Further, the covered glass beaker containing LG sample with the solution was kept in an oven at $500^{\circ} \mathrm{C}$ (adiabatic temperature obtained using HSC-Chemistry) for the ON-OFF cycle of 5-3 min for $1 \mathrm{~h}$. After $1 \mathrm{~h}$ solution was kept for $1 \mathrm{~h}$ at a temperature of $120^{\circ} \mathrm{C} .50 \%$ of the samples were having bubbles due to the melting of the interlayer. The dipped
LG samples were kept horizontal into the solution have resulted in no bubbles. It was tried in the experimentation that the PVB interlayer even if melt, do not flow within or outside LG; horizontally kept samples have produced comparatively desired results. A ceramic fiber cloth acquired from the local source (easily withstand temperature up to $600^{\circ} \mathrm{C}$ ) was used for wrapping the boundaries having interlayer tightly so that PVB does not flow outside LG. The chemical equation demonstrating the material phases during the reaction of Potassium nitrate and Carbohydrazide is given by Equation 1:

$$
\begin{aligned}
& 8 \mathrm{KNO}_{3}(\text { solid })+5 \mathrm{CH}_{6} \mathrm{~N}_{4} \mathrm{O}(\text { solid })=4 \mathrm{~K}_{2} \mathrm{O}(\text { aqueous }) \\
& +5 \mathrm{CO}_{2}(\text { gas })+14 \mathrm{~N}_{2}(\text { gas })+15 \mathrm{H}_{2} \mathrm{O}(\text { liquid })
\end{aligned}
$$

In the second method, Lithium Nitride $\left(\mathrm{LiNO}_{3}\right)$ was used instead of $\mathrm{KNO}_{3}$ as the melting point of Lithium Nitride is quite low $\left(255^{\circ} \mathrm{C}\right)$ than $\mathrm{KNO}_{3}$, at the same time effective ion radius of $\mathrm{Li}^{+}(0.760 \mathrm{~nm})$ and mobility is higher and minimum penetration time is $(20 \mathrm{~min})$ is lower than $\mathrm{KNO}_{3}$. The temperature of the oven, in this case, is kept $270^{\circ} \mathrm{C}$; bubbling was not reported in any of the LG samples. The consequences of these methods include once the water evaporates, the steam starts pushing the cover violently; however, thicker and stronger beaker and cover overcome this difficulty.

The third attempted method includes clay coating (saturated with salts) of LG sample. In this method the LG samples were first cleaned using ionized water, the similar mixture of salts and water was prepared as before, further $7 \mathrm{gm}$ of clay was mixed into the saltswater mixture until homogeneous thick mixture is obtained. The LG surfaces were coated with the clay-saltswater mixture and boundaries were tightly covered by ceramic fiber cloth. The wrapped coated LG sample was kept in the oven for $1 \mathrm{~h}$ at $500^{\circ} \mathrm{C}$. Once the $\mathrm{LG}$ sample was cooled in the oven, the clay was cleaned up from be LG sample surface and later the cleaned LG samples were kept in the oven for baking at $100^{\circ} \mathrm{C}$ for half-an-hour.

The fourth method for LG treatment utilized localized rapid heating method suggested by Li et al. (2015). A little modification to the suggested method was made by utilizing the fused silica wafer coated with a thin graphene layer to heat the clay coated surface of the LG. However, the result obtained by Li et al. (2015) could not be reproduced as the substrate was different in this case. However, some success was observed with the method of localized heating of glass suggested in US patent number $8816252 \mathrm{~B} 2$, in which eclectically conductive heating element was utilized to produced a localized heating effect on the surface of the glass. The results of the later method (US patent number 8816252 B2) used for localized heating of LG surface are discussed in the present work.

Finally, microwave (with a power of $1000 \mathrm{~W}$ ) baking (as the fifth method) was tried for the ion exchange process for LG samples. The method requires 15-20 min 
for the treatment of LG surface. The LG sample was prepared and coated with water-salts-clay mixture, the boundaries of LG sample was tightly wrapped with ceramic fiber cloth. Further, the sample was kept horizontally into the microwave for $10 \mathrm{~min}, 2 \mathrm{~min}$ continuously ON and $15 \mathrm{sec}$ OFF (the cycle time was determined after many experimental runs). After $10 \mathrm{~min}$ of microwave baking and cooling inside the microwave, the sample was taken out and dried clay was cleaned from the sample with acetone. The sample was kept in the oven at $100^{\circ} \mathrm{C}$ for $20 \mathrm{~min}$ for further drying out. The focus of present work is to increase the load bearing ability of LG with the thermo-chemical treatment. The detailed study on effects of each method on LG surface (including the depth profile of $\mathrm{K}+($ Method 1) or $\mathrm{Li}+$ (Method 2)) and an interface between PVB and glasses could be considered as the future work for better understanding of the mechanics of each treatment method. The compressive stress of the LG surface was varied from 200 to $600 \mathrm{MPa}$.

In the present work, bending test of eighteen LG samples (of six different types- three untreated and three treated LG samples with each of the five methods) was performed in accordance with ASTM D790-03. The LG samples (after finishing operation at the edges) of $184.32 \times 40 \times 11.52 \mathrm{~mm}^{3}$ were placed on two supports at corners, a force is applied at the center of the samples and the resulting displacements were recorded. The test was performed at the ambient temperature. As per the standard, the test is completed if the specimen reaches $5 \%$ deflection of the thickness or fractured before it. In the present work, all the LG samples were fractured before reaching the $5 \%$ of deflection. Fig. 3 shows the experimental set ups used for sample preparation and bending test.

The results of experimentation were compared with the simulation (using ANSYS 14.5) results. The linear elastic model was used; the properties of glass, PVB, the material model and simulation method used are similar as used in (Vedrtnam and Pawar, 2017a; 2017b; 2017c; Sharma et al., 2017; Vedrtnam and Pawar, 2017d). The flexural behavior of LG-PVB samples was simulated using FE linear elastic model in ANSYS 14.5 (for threepoint bending test). The results of experimentation were complimented by the FE simulation. The pattern of total displacements of LG samples was observed at the fracture loads for explaining the fracture pattern of the LGs. The material properties of the glass and inter-layers are taken from the manufacturer's data table (Vedrtnam and Pawar, 2017a; 2013; 2017b; 2017c).

$\begin{array}{lcl} & \text { Glass } & \text { PVB } \\ \text { Young's modulus }\left[\mathrm{N} / \mathrm{mm}^{2}\right] & 70,000 & 220 \\ \text { Poisson ratio }[-] & 0.23 & 0.495 \\ \text { Density }\left[\mathrm{kg} / \mathrm{m}^{3}\right] & 2500 & 1100\end{array}$

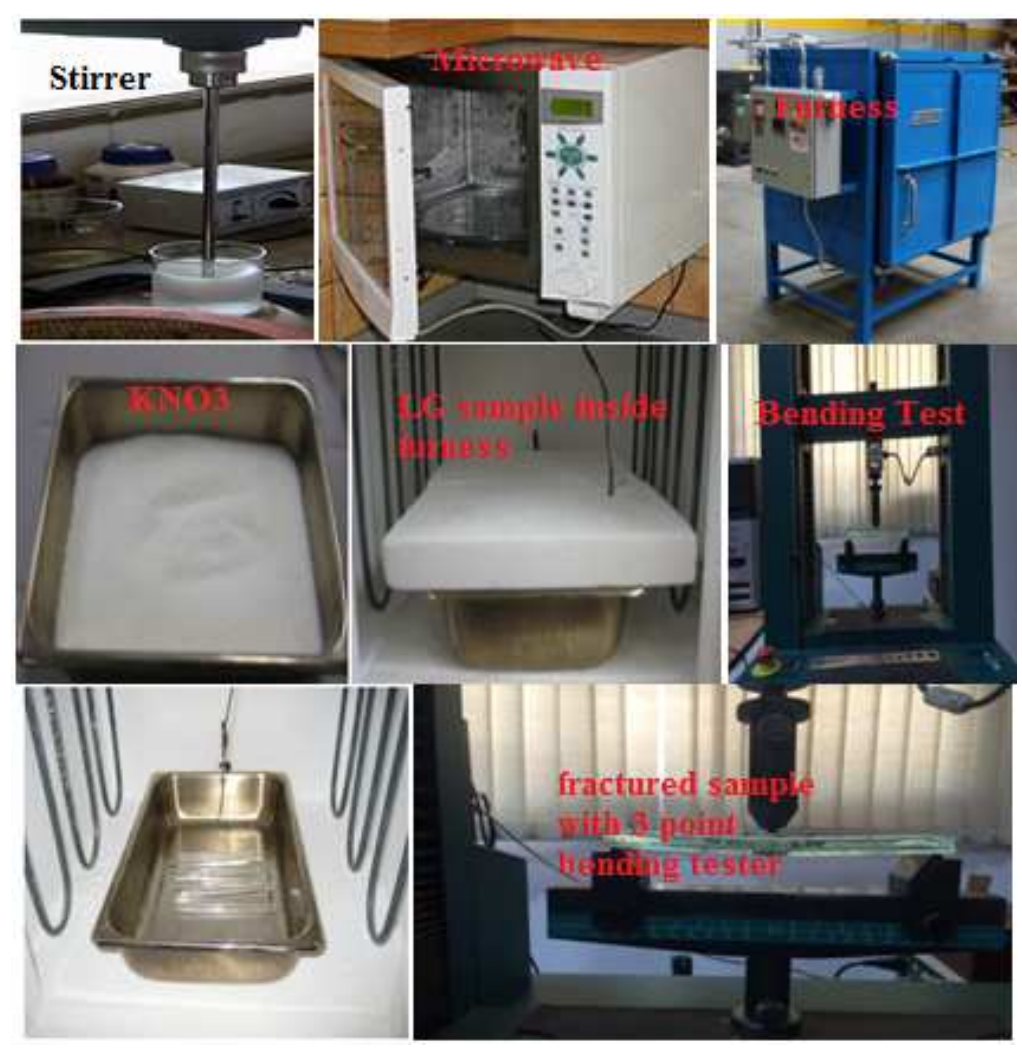

Fig. 3: Experimental set ups for sample preparation and bending test 
The simulation was performed considering the experimental set-ups; three-point bending experimental set-up and loading condition were also simulated assuming the similar boundary and the loading condition as used in experimentation. During three-point bending simulation, it was considered that $\mathrm{LG}$ is simply supported at the corners and load (line) is applied at the center. The simulation was performed for untreated samples. The fine mesh having tetrahedron elements (number of nodes 25872, number of elements 5966) was used. The grid refinement study has not reported significant changes in the results. The simulation considering the effect of treatment methods on LG is considered as the future scope. The effect of treatment can be simulated using ANSYS by introducing the compressive stresses on the surface of LG in advance before the application of bending load.

\section{Results and Discussion}

Table 1 show the results obtained from the testing of 18 samples including 3 untreated samples and 15 treated samples (3 samples from each treatment method). The maximum deformation at the fracture load and the maximum normal stress at the fracture load obtained by the numerical simulation are also reported. The results of the numerical model presented in Table 1 are explained and compared with the experimental results in the later section. Table 1, Fig. 4 collectively show the loads at the fracture, the deformations (during experimentation), deformations (from the numerical model), normal stresses (from the numerical model), force-extension curves and photographs of untreated fractured samples. Sample 1 has the least fracture load, deformation and the normal stress out of three tested untreated samples. The loadextension diagram of the sample 1 shows that around $220 \mathrm{~N}$ load and $0.6 \mathrm{~mm}$ extension the first fracture occurred as the cracks are generated across the width in the lower glass plate near the mid-span region and the force decreases suddenly, then the load drops at negligible extension up to $150 \mathrm{~N}$ the force further increases and reaches up to a maximum value of $274 \mathrm{~N}$, then the upper glass plate cracks then load again decreases rapidly. The zone of fracture is spread around the mid-region of the sample for $35 \mathrm{~mm}$, multiple cracks and nonuniform fracture is visible in the photograph of the first sample. The second untreated sample has $19.41 \%$ higher load at fracture than sample 1 whereas, the maximum deformation is $4.44 \%$ higher. The load-extension curve of sample 2 indicates that the load almost linearly increases with an extension up to $340 \mathrm{~N}$, at which the fracture occurred first in lower glass plate around mid-span region than the force goes down sharply to a value around $250 \mathrm{~N}$, further the sample start taking load and at around $255 \mathrm{~N}$ the upper glass plate also observe fracture. The fracture pattern and the region of fracture is similar to sample 1 , however, the fracture zone is $2 \mathrm{~mm}$ shorter in sample 2 . Sample 3 has $21.11 \%$ higher load at fracture than sample 1, the maximum deformation experienced is also the highest in the sample 3 . The load-extension extension curve shows the multiple fractures, the load rises with the extension to the maximum value of 343 $\mathrm{N}$ at which the fracture at lower glass plate occurred. The load then sharply dropped to a value of $200 \mathrm{~N}$, further it raises to a value of $230 \mathrm{~N}$, then it drops a bit and final fracture is reported at $300 \mathrm{~N}$ and $1.27 \mathrm{~mm}$ extension. The fracture zone is more towards the left side of mid-span region, possibly due to the presence of the defect in that region. LGs do not have grains or long-range order expect in the interlayers. The microstructural barriers (second phase particles or grain boundaries during fracture at the surfaces of LG) are also not present in LG so pre-existing or newlyinitiated cracks are not arrested locally, that result-in easy initiation and propagation of the crack in LG. The cracks in LG initiate from defects (voids), surface flaws such as polishing scratches, shear bends and boundary defects. The bending loading induces the microstructural damage and further failure of LG; however, LGs are seldom designed based on optimized microstructures for bending strength. It is stated in the literature that fracture behavior of glass can be explained by free volume theory (however this theory explains fracture of bulk metallic glasses) (Liu et al., 2009). Since the fracture initiation is controlled by local atomic arrangements and free volume shear bends, boundary defects (crack) propagation can happen at much lower load during bending loading in LG. The crack growth in LG could also be also explained using Paris power law equation (applicable for bulk metallic glasses and composites) as reported in (Gilbert et al., 1999). For window glass, Griffith flaws at the surfaces and edges are generally the basis of fracture. Further, the fractured surface during the experiment showed that the bending-crack-growthregion has the distinct striations. The striations formation in LGs could be due to blunting and resharpening during bending. The model has reported in the literature states that the crack-propagation rate is directly proportional to the range of crack-tip-opening displacement (Gilbert et al., 1999). But in LG, there is a non-uniform crack extension which result-in larger striation spacing. At the crack tip, the small plastic zone is formed and further, many crack branches are developed from that zone and after that crack propagates in the favourable direction and LG fails very quickly as the stress intensity factor reaches the fracture toughness of LG. 


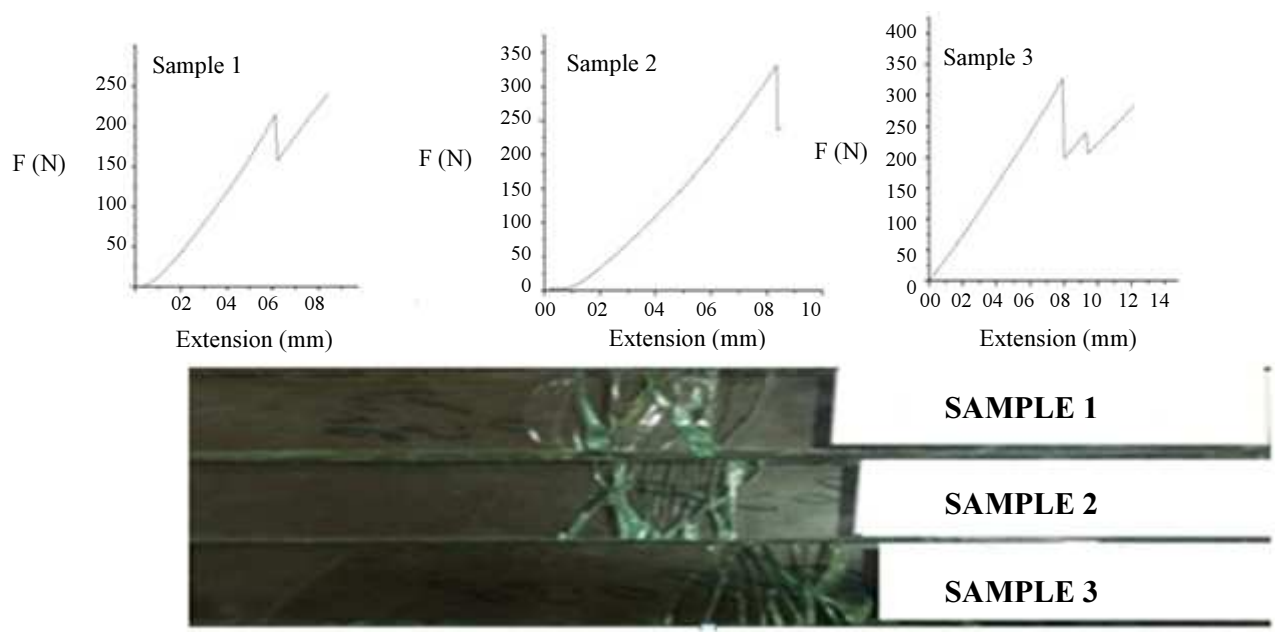

Fig. 4: Untreated samples: Force $(\mathrm{N})$ Vs Extension $(\mathrm{mm})$ diagram and fractured samples

Table 1: Results of 3-Point bending test

\begin{tabular}{|c|c|c|c|c|c|}
\hline \multirow[b]{2}{*}{ Method } & \multirow[b]{2}{*}{ No. } & \multicolumn{2}{|c|}{ Experimentation } & \multicolumn{2}{|c|}{ Simulation } \\
\hline & & $\mathrm{F}(\mathrm{N})$ & $\mathrm{D}(\mathrm{mm})$ & $\mathrm{D}(\mathrm{mm})$ & Normal stress (MPa) \\
\hline \multirow[t]{3}{*}{ Untreated } & 1 & 274 & 0.86 & 0.07 & 7.69 \\
\hline & 2 & 340 & 0.90 & 0.08 & 8.32 \\
\hline & 3 & 343 & 1.27 & 0.08 & 8.39 \\
\hline \multirow[t]{3}{*}{1} & 1 & 450 & 1.22 & 0.11 & 11.98 \\
\hline & 2 & 391 & 1.35 & 0.09 & 9.22 \\
\hline & 3 & 340 & 0.95 & 0.08 & 8.32 \\
\hline \multirow[t]{3}{*}{2} & 1 & 390 & 1.82 & 0.09 & 9.22 \\
\hline & 2 & 590 & 2.52 & 0.18 & 14.17 \\
\hline & 3 & 595 & 2.48 & 0.19 & 14.20 \\
\hline \multirow[t]{3}{*}{3} & 1 & 444 & 1.50 & 0.10 & 11.86 \\
\hline & 2 & 261 & 1.18 & 0.07 & 7.16 \\
\hline & 3 & 450 & 1.52 & 0.11 & 11.98 \\
\hline \multirow[t]{3}{*}{4} & 1 & 340 & 1.58 & 0.08 & 8.32 \\
\hline & 2 & 344 & 1.38 & 0.08 & 8.38 \\
\hline & 3 & 430 & 1.29 & 0.07 & 11.52 \\
\hline \multirow[t]{3}{*}{5} & 1 & 550 & 2.40 & 0.13 & 13.39 \\
\hline & 2 & 441 & 1.90 & 0.11 & 11.77 \\
\hline & 3 & 540 & 2.40 & 0.12 & 13.07 \\
\hline
\end{tabular}

The result obtained from testing of untreated LG samples shows that the maximum load variation before the fracture is from $343 \mathrm{~N}$ to $274 \mathrm{~N}$ and the deflection varies from $1.27 \mathrm{~mm}$ to $0.86 \mathrm{~mm}$. The variation obtained is due to the non-uniform behavior of glass that depends on surface (crack) and edge defect, non-uniformity of the chemical composition, the duration of the loading, characteristics of glass manufacturing techniques (including annealing, environmental parameters), the geometry production, cutting, storage and transportation of the sample, which requires further intensive investigation (Min'ko and Vladimir, 2013).

The results obtained from the testing of LG samples treated by method 1 (Table 1) and show that the maximum load before the fracture varies from $450 \mathrm{~N}$ to $340 \mathrm{~N}$ and the deflection varies from $1.35 \mathrm{~mm}$ to 0.95 $\mathrm{mm}$. The maximum load withstands by treated samples by method 1 is higher at an average from untreated LG samples. Figure 5 demonstrates the load-extension curves obtained from the testing of treated LG samples (by method 1). The curves clearly show that the loadextension curves are having variation in maximum fracture load and deflection for different samples of the same type. The curve for sample 1 shows that the force increases and reaches up to a maximum value of $450 \mathrm{~N}$, then a crack is generated across the width in the lower glass plate near the mid-span region and the force decreases suddenly. It is observed from the curve that the force again increases slightly and when the upper glass plate cracks then it decreases rapidly. In the sample no. 1 the maximum deflection is $1.22 \mathrm{~mm}$. The fracture zone in the first treated sample is shorter than the untreated 
samples one side it is just $7 \mathrm{~mm}$ and another side it is 24 $\mathrm{mm}$ around the mid-span region. The load-extension curve of sample 2 shows that the force increases and goes up to a value of $305 \mathrm{~N}$ than at this point a crack is generated in the lower glass plate and the force decreases rapidly up to a value of $150 \mathrm{~N}$. The load further rises to the maximum value of $450 \mathrm{~N}$ before fracture. In the sample no. 2 the maximum deflection is $1.35 \mathrm{~mm}$. The fracture zone in sample 2 is wider than the sample 1 and similar on both sides of the sample. The load-extension curve of sample 3 shows that the maximum load and deflection are $340 \mathrm{~N}$ and $0.95 \mathrm{~mm}$ respectively. The cracks are generated near the mid-span region and the cracks are not very dense in the sample no. 3. However, the one side of the sample has the widest zone of fracture and the fracture lines are concentrated on the other side of the sample. The bending strength, deformation is higher and fracture zone is shorter in the treated samples when compared to untreated samples; the reason for same is the reduced defects in samples and higher compressive strength of the surface of LG. It is expected that ion exchange and sample refinement due to treatments leads to improved bending strength of the LG samples.

Figure 6 demonstrates the load-extension curves obtained from the testing LG samples treated by the method 2. The curves reflect that fracture pattern, maximum load at fracture and the deflection are considerably different compared to the untreated and treated samples by method 1 . The maximum load variation before the fracture is from $390 \mathrm{~N}$ to $595 \mathrm{~N}$ and the deflection varies from $1.82 \mathrm{~mm}$ to $2.52 \mathrm{~mm}$. The load-extension curve of sample no. 1 reflects that the force increases and reaches up to a value of $348 \mathrm{~N}$, then after a crack is generated across the width in the lower glass plate near the mid-span region and the force suddenly drops to $210 \mathrm{~N}$. Further, the force again started increasing and reaches to a maximum value of $390 \mathrm{~N}$ at which the sample is completely fractured. In the sample no. 1 the maximum deflection is $1.82 \mathrm{~mm}$. The fracture zone of the first sample is shortest and at the mid-span region of the sample where the load was applied.

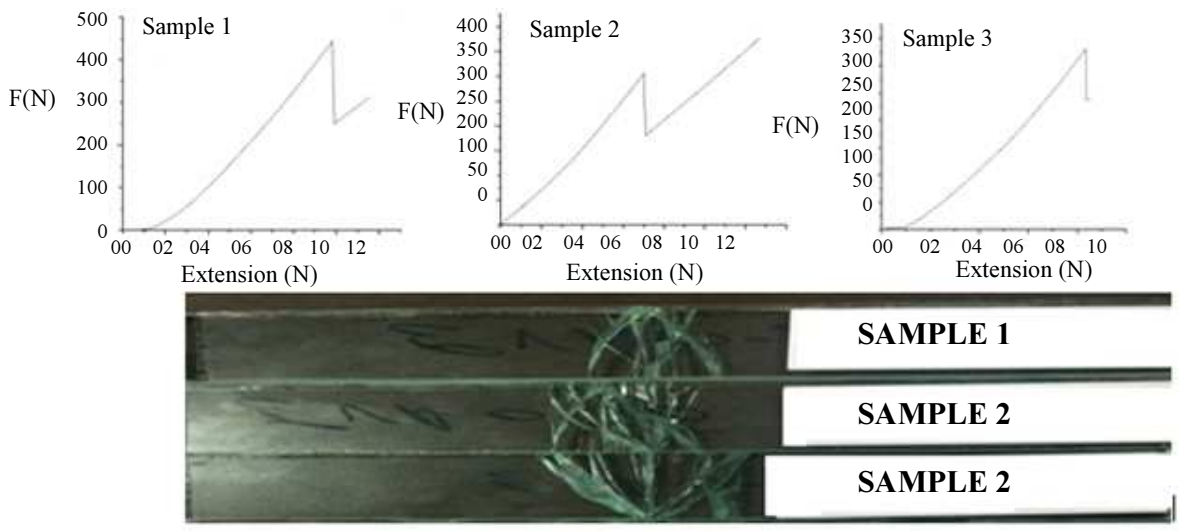

Fig. 5: Treated samples (Method 1): Force $(\mathrm{N})$ Vs Extension $(\mathrm{mm})$ diagram and fractured samples

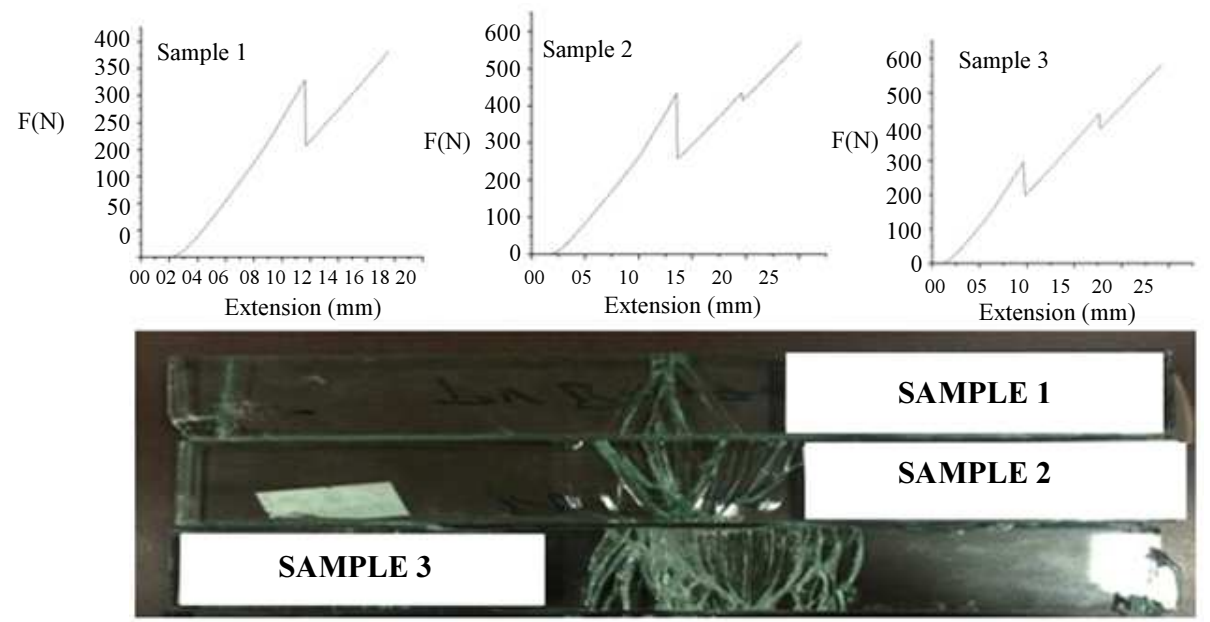

Fig. 6: Treated samples (Method 2): Force (N) V13-sgamrs Extension (mm) diagram and fractured samples 
The load-extension curve of sample no. 2 reflects that the force increases and goes up to a value of $443.5 \mathrm{~N}$, when a crack is generated in the lower glass plate and the force decreases rapidly to a value of $270 \mathrm{~N}$ and then increases up to a value of $450 \mathrm{~N}$ at which one additional small fracture is visible. The force drops slightly and further increases to the maximum value of $590 \mathrm{~N}$ and the maximum deflection reaches $2.52 \mathrm{~mm}$. Sample 2 has wider fracture zone sprayed for $42 \mathrm{~mm}$ in the mid region. The load-extension curve of sample no. 3 reports fractures at $300 \mathrm{~N}, 440 \mathrm{~N}$ and finally, at the maximum load $593 \mathrm{~N}$. The deflection at the maximum load was $2.48 \mathrm{~mm}$. The fracture zone of sample 3 is widest and sprayed to $59 \mathrm{~mm}$ around mid-region. The treated samples from method 2 have $42.35 \%$ higher maximum load at fracture than the untreated samples while $24.36 \%$ higher maximum load at fracture than the samples treated with method 1. In general, the higher strength leads to the lower deformation but the trend reported from LG suggest otherwise as the data is reported while samples have experienced multiple fractures and also the fracture of LG sample depends on impurities, cracks, boundary and surface defects, chemical composition of glass and interlayer, the method of preparation of glass, interlayers and LG, type of glass and the method of treatment of LG. As it is observed that LG samples treated with $2^{\text {nd }}$ method have the higher strength at an average than method 1, this may be due to $\mathrm{LiNO}_{3}$ was used in method 2 instead of $\mathrm{KNO}_{3}$, the lower melting point of $\mathrm{LiNO}_{3}$, higher effective ion radius of $\mathrm{Li}^{+}(0.760$ $\mathrm{nm})$, mobility and lesser minimum penetration time than $\mathrm{KNO}_{3}$ causes effective thermo-chemical reaction in method 2. Thus, the method 2 is preferable over method las method 2 handles the constraints of treatment of LG (like a lower melting point of the interlayer and avoiding the flow of the interlayer) in a better manner. It is also observed generally that the LG samples that are having wider fracture zone have sustained higher load before fracture; this is due to wider fracture zone represents multiple fractures that require an additional load. However, this explanation is not sufficient as a few exceptions are also reported during experimentation. It requires further intensive investigation for establishing an acceptable relation/explanation for load before fracture, deformation and the spread of fracture zone for LG during bending test. This estimation could be useful for protective structures and other structural applications where LG is used.

Figure 7 demonstrates the results obtained from the testing of LG samples treated with method 3. The maximum load variation before the fracture is from 261 $\mathrm{N}$ to $444 \mathrm{~N}$ and the deflection varies from 1.18 to 1.52 $\mathrm{mm}$. The load-extension curves indicated the similar pattern as indicated by the LG treated from method 2, however, the maximum fracture load before fracture at an average is lesser in this case. The load-extension curve of sample no. 1 reflects that the force increases and reaches up to $255 \mathrm{~N}$, when a crack is generated across the width in the lower glass plate near the mid-span (similar to the previous fracture patterns) and the force decreases. After that, the upper glass plate again resisted load, the force again increases; four fractures are visible at $250 \mathrm{~N}, 247 \mathrm{~N}, 322 \mathrm{~N}$ and finally at $444 \mathrm{~N}$ in the loadextension curve. In the sample no. 1, the maximum deflection is $1.5 \mathrm{~mm}$. Sample 1 is having extended fracture zone, the fracture is also reported a little far from the mid-span region (as shown in Fig. 7); that may be due to preexisting crack or any defect at that place. The load-extension curve of sample no. 2 shows that the force increases and goes to a value of $220 \mathrm{~N}$, the crack is generated in the lower glass plate and the force decreases and then again increases rapidly and reaches up to 240 $\mathrm{N}$, further, two more fractures are witnessed by the loadextension curve. The final fracture has occurred at $261 \mathrm{~N}$ and the deflection at that point is $1.76 \mathrm{~mm}$. the fracture zone of sample 2 is $32 \%$ shorter than sample 1 . The load-extension curve of sample no. 3 shows that the force increases and reaches a value of $350 \mathrm{~N}$ and then at this point a crack is generated across the width in the lower glass beam and force decreases slightly and goes to a value of $340 \mathrm{~N}$. The force further increases rapidly and goes up to a maximum value of $450 \mathrm{~N}$ at which final fracture is reported. In the sample no. 3 the maximum deflection is $1.52 \mathrm{~mm}$. Sample no. 3 is having less dense but multiple fractures across the length of the sample around the mid-span region, which clearly showed the presence of pre-existing cracks, defects or impurities in LG sample. Thus, it can be concluded that clay coating method (method 3) improves the LG performance but its effect are not uniform throughout the LG and impurities and defects remained in LG samples after this treatment. However, future studies suggesting modifications in the method of application of clay and modifications in this method may make it a potential process for treatment as the strength in sample 1 and sample 3 is increased substantially using this method.

Figure 8 demonstrates the results obtained from the testing of LG samples treated with method 4. The maximum load variation before the fracture is from 340 $\mathrm{N}$ to $430 \mathrm{~N}$ and the deflection varies from $1.29 \mathrm{~mm}$ to $1.58 \mathrm{~mm}$ in the LG samples treated with method 4 . The load-extension curve of sample no. 1 indicates that the force increases and reaches up to a value of $320 \mathrm{~N}$ at which crack is generated across the width in the lower glass beam near the mid-span region (as in most of the earlier cases). It is followed by two subsequent fractures as reflected by the curve, the force again started increasing slightly and reaches to a value of $230 \mathrm{~N}$ before the second fracture. Further, it decreases slightly and then increases rapidly and goes to a maximum value of $340 \mathrm{~N}$ at which upper glass ply experience the 
breakage in and around the middle span of the sample at which the maximum deflection is $1.58 \mathrm{~mm}$. The fracture of the LG sample is visible at 3 different locations; that shows the presence of the pre-existing crack, defect or impurity. The load-extension curve of sample no. 2 indicates that force increases and goes up to value of 305 $\mathrm{N}$ then at this point a crack is generated in the lower glass plate followed by one more fracture at the maximum force $344 \mathrm{~N}$. The sample no. 2 has least extended fracture zone, however, an additional fracture is also observed at right side of the mid-span region; that shows presence of defect/impurity/crack in that region. In the sample no. 2 the maximum deflection is $1.16 \mathrm{~mm}$. The load-extension curve of sample no. 3 indicates that the force increases and goes up to the value of $370 \mathrm{~N}$ then at this point a crack is generated in the lower glass plate and the force decreases rapidly. Later, the force further increases and goes to a value of $365 \mathrm{~N}$, then again it decreases slightly and then increases and goes up to a maximum value of $435.5 \mathrm{~N}$. In the sample no. 3 the maximum deflection is $1.48 \mathrm{~mm}$.
Figure 9 demonstrates the results obtained from the testing of $11.52 \mathrm{~mm}$ thick LG-PVB samples treated with the method 5. The maximum load variation before the fracture is from $441 \mathrm{~N}$ to $550 \mathrm{~N}$ and the deflection varies from $1.9 \mathrm{~mm}$ to $2.4 \mathrm{~mm}$ in the LG samples treated with method 5. The load-extension curve of sample no. 1 shows that the force increases and reaches up to a maximum value of $435 \mathrm{~N}$ then a crack is generated in the regular manner as given before in the lower glass plate, this fracture is followed by one more fracture at $450 \mathrm{~N}$ followed by the final fracture at $550 \mathrm{~N}$ with the maximum deflection of $2.4 \mathrm{~mm}$. The fracture zone is shorted and the fracture pattern is comparatively uniform for sample1. The load-extension curve of sample no. 2 shows that the force increases and goes to a value of 405 $\mathrm{N}$ at which a crack is generated in the lower glass beam and the force decreases and then again increases rapidly and reaches a maximum value of $441 \mathrm{~N}$ at a maximum deflection of $1.9 \mathrm{~mm}$. The fracture pattern is similar to sample 1; however, a crack far from the mid-span region can be noticed in sample 2 .
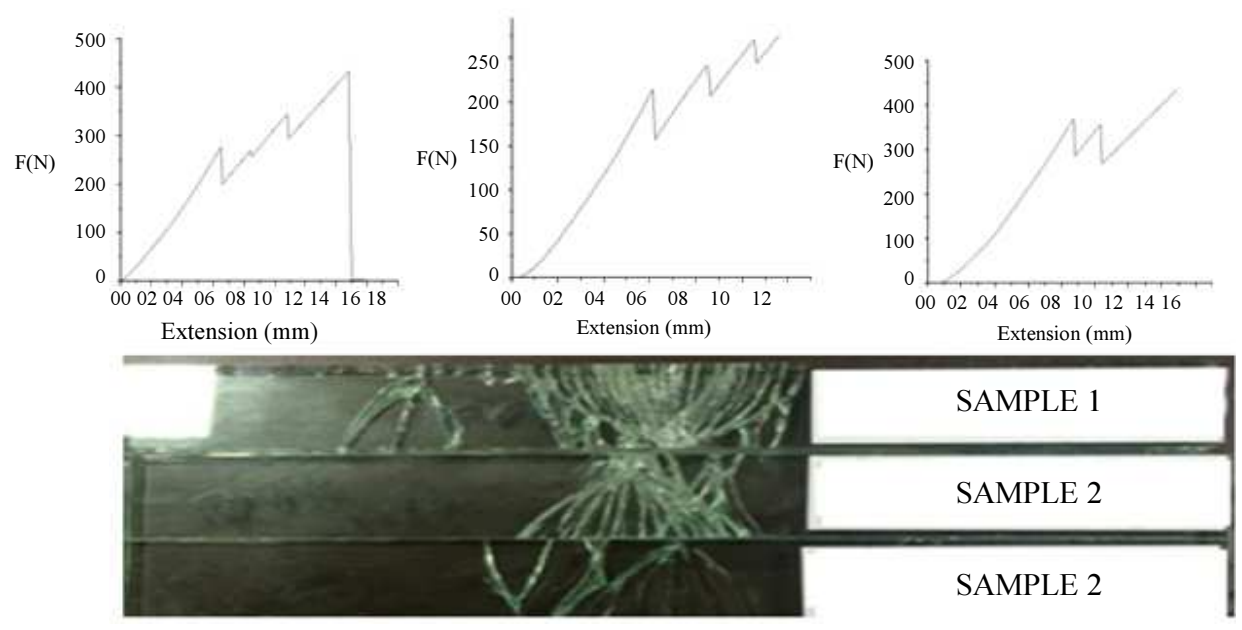

Fig. 7: Treated samples (Method 3): Force (N) Vs extension (mm) diagram and fractured samples

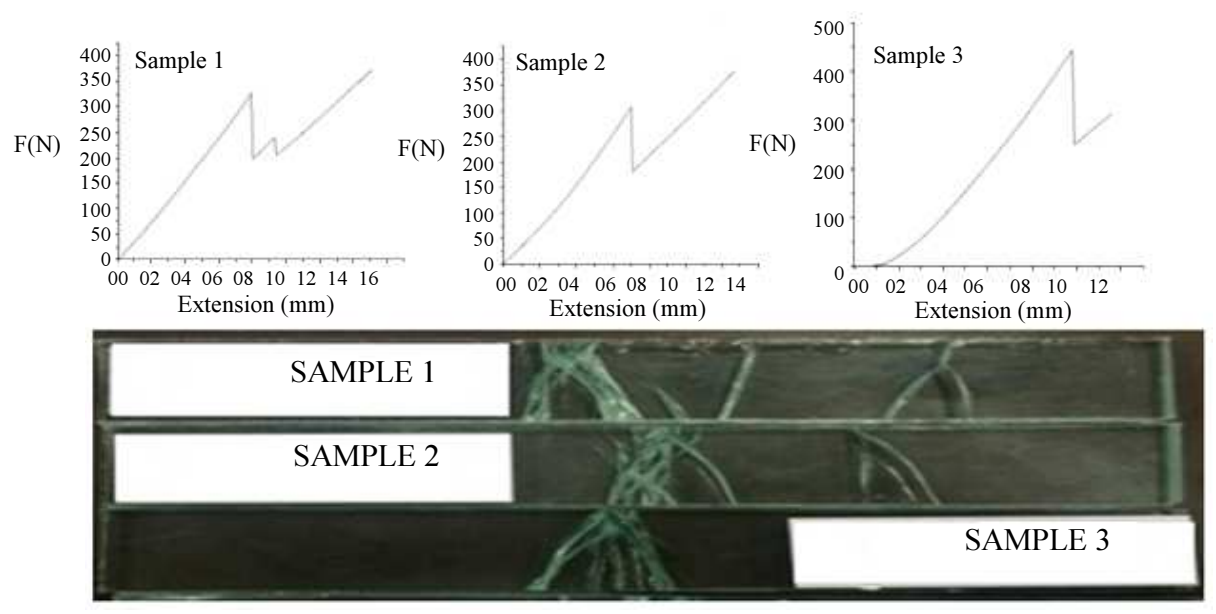

Fig. 8: Treated samples (Method 4): Force (N) Vs extension (mm) diagram and fractured samples 
The load-extension curve of sample no. 3 shows similar behavior as shown by the load-extension curve of sample no. 1 but with the maximum load of $540 \mathrm{~N}$ and the deflection of $2.4 \mathrm{~mm}$ (same as in sample 1). The fracture zone is shorter in the $3^{\text {rd }}$ sample as well. Thus, it can be concluded safely that the microwave baking has shown good results as bending strength is significantly improved and fracture pattern is also modified. Overall, the method 2 and the method 5 have shown the better results and have significant potential to be used as the treatment method of LG. It is also worth mentioning that the maximum tensile stress is always found right in the middle of the sample on the bottom side and that is exactly where crack initiation is expected. The reason, why the first crack in the glass may deviate from that position in the experiments is the natural distribution of Griffith flaws on the surfaces and (more importantly for these specimens) edge flaws in LG specimens. Figure 10a represents the final fracture loads for untreated and treated samples by the all five methods. Fig. 10a clearly reflects the superiority of method 2 and method 5 over other treatment methods. Figure 10b represents load at which the 1st fracture (could be correlated with the strength of LG due to the compressive stresses introduced due to treatment on the surface of LG) has occurred in the treated and untreated samples.

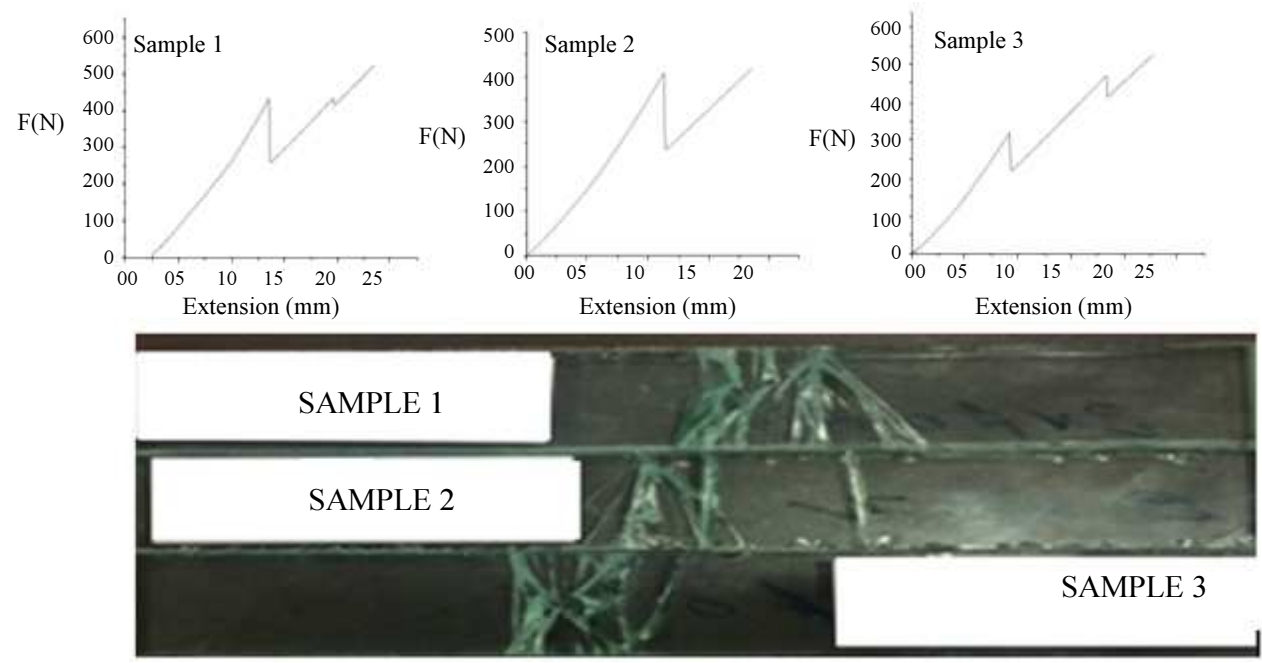

Fig. 9: Treated samples (Method 5): Force (N) Vs Extension (mm) diagram and fractured samples

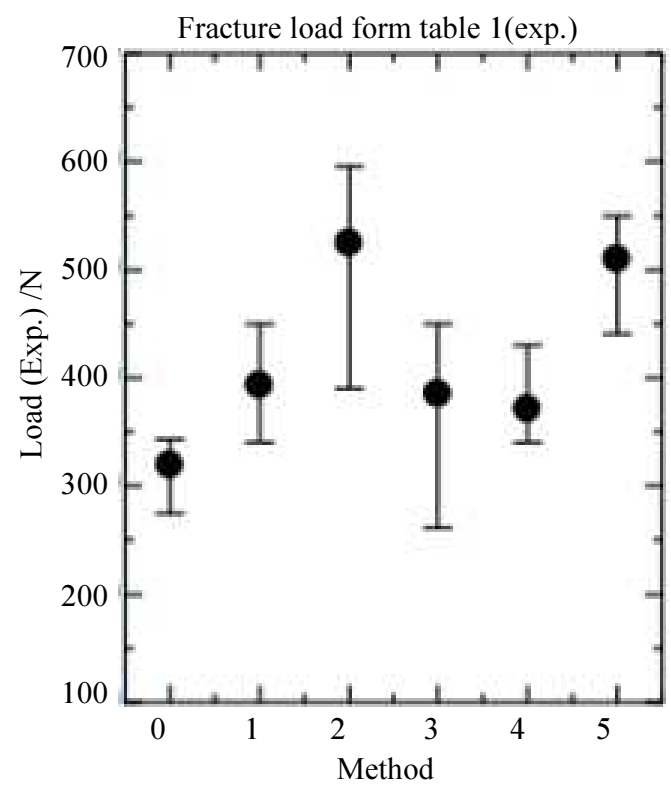

(a)

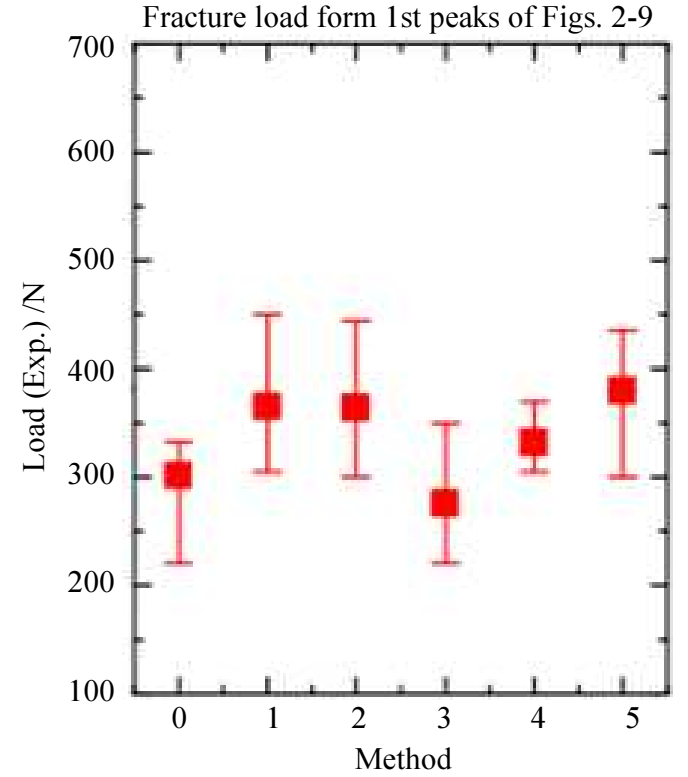

(b)

Fig. 10: (a) Final fracture load (b) Load at 1st fracture of LG samples 


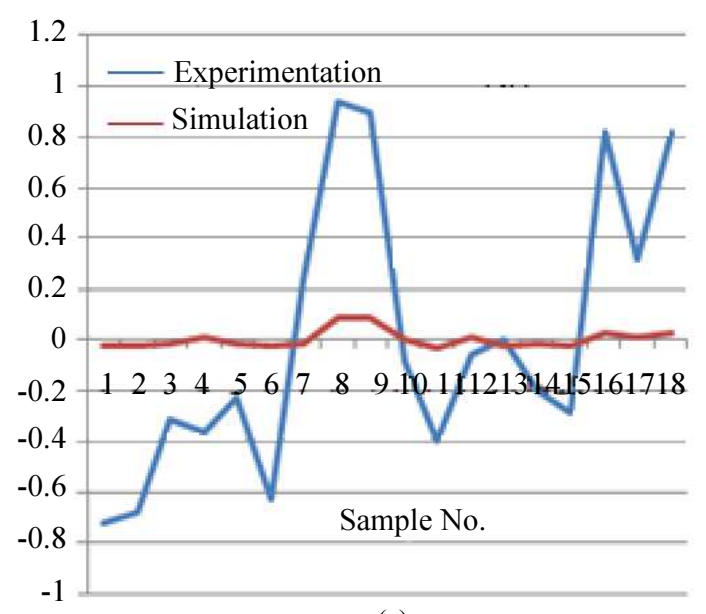

(a)

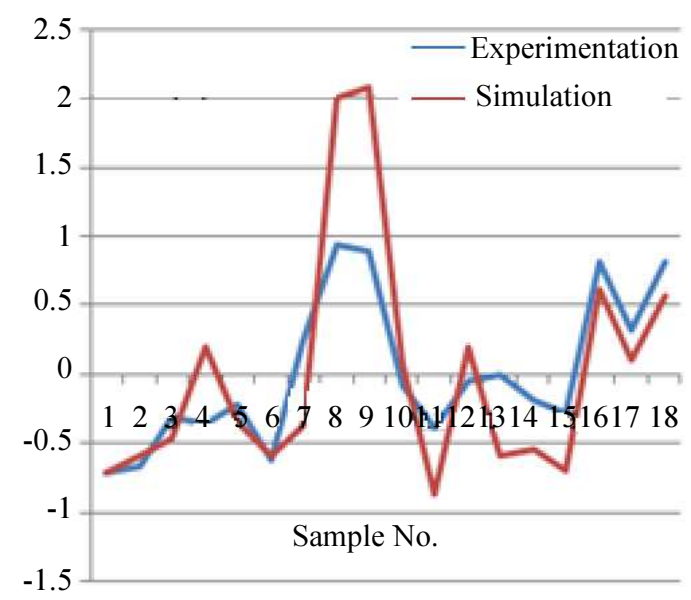

(b)

Fig. 11: Variation from mean values of deflection in experimentation and simulation (a) Without error correction (b) With error correction

The Fig. 10b shows that the methods 1, 2 and 5 improve the load bearing ability of LG before the first fracture. However, the maximum load (modulus of rupture) of LG after each treatment is affected not only by properties of glass treated but also by properties of the interface between PVB and glasses. The method 2 and 5 resulted significant improvement in the post 1 st fracture performance of LG. Of course, edge effects also affect the strength value, thus, the Ring-on-Ring or Ball-onRing test could be performed in future to evaluate the strength of LG without the influence of the edges. To study the response of treated glass during fire condition will also be interesting and considered as future work (Bedon, 2017; Zhang and Bedon, 2017).

\section{FE Simulation Results}

ANSYS 14.5 software is used to obtain deflection and stresses at the various loads at which the various specimens fractured during experiments. The FE simulation results are also shown in Table 1 . The result obtained from software simulation clearly indicates that the deflections obtained experimentally are considerably larger than the software results. The reason for same is that the results obtain from experiments shows deflection when specimens have experienced multiple fractures and also fracture of the glass quite often have differentiation when simulated with software results. The physical inhomogeneity in the glass is also the reason of same, which is resulted due to the transition of glass from the viscous to the brittle condition taking place at a different rate in different parts of the glass. This type of inhomogeneity is connected with the structural changes. In general, it can be considered as a thumb rule for glasses that the simulation results of the unbroken case can never match to the data obtained during experimentation from a broken sample; still, a comparison is presented for observing the similarity in trends of experimental and simulation results. The Fig. 11a shows the variation of the deflection obtained from the mean value of experimental and simulation results of LG respectively treated from all the methods. It is clearly reflected in Fig. 11a that the numerical and experimental results have some variation; however, the trend is considerably similar. The reason of variation is that the multipurpose numerical algorithm used in the present work could not follow the effect of treatment on the LG surface and a highly devoted specialized numerical algorithm is required for each treatment method to capture the actual behavior of LG after treatment from a particular method. The development of numerical simulation algorithm that can capture the effect of treatment accurately can be considered as future work. There is also a need for numerical the method that could simulate the multiple fractures experienced by LG during bending or any other loading condition. Figure $11 \mathrm{~b}$ shows the comparison of experimental and numerical results. The Fig. $11 \mathrm{~b}$ reflects a good match between experimental and simulation results. The Fig. 11b was made considering an error factor of 24.82 (a constant value) which is multiplied by the value of deflection obtained from simulation results. The value of error factor is calculated based on the difference between the mean values of deflection in simulation and experimentation. The corrected values of deflection obtained from the simulation have visibly the same trend as obtained in the experimentation. A better error estimate (may be considered as future work) can be introduced during the constitution of a specialized numerical model for the discussed problem. It can be concluded from Fig. $11 \mathrm{~b}$ that trend followed by the experimental results is a good match to the trend followed by the simulation output. 


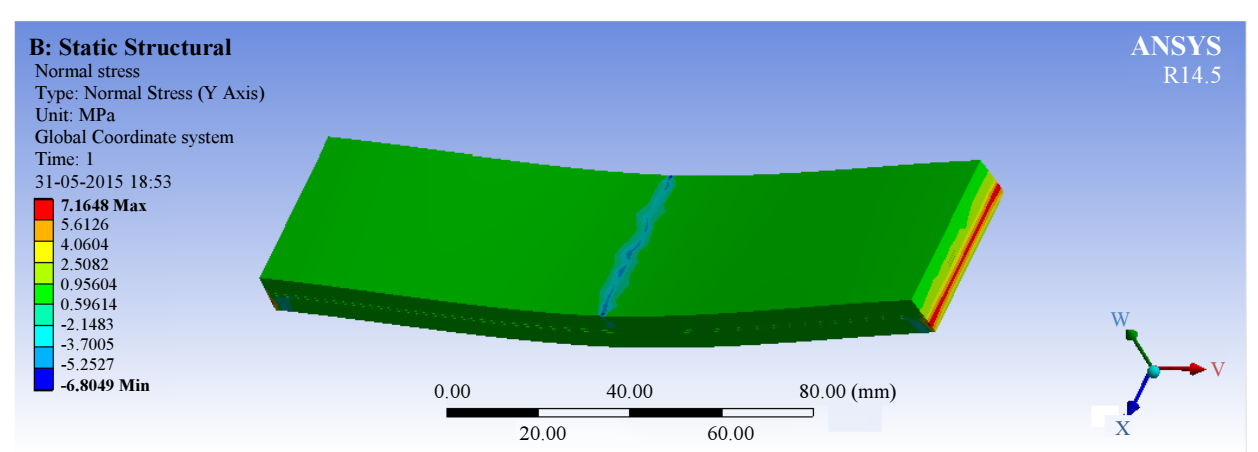

Fig. 12: Sample simulation output: Normal stress at $261.66 \mathrm{~N}$

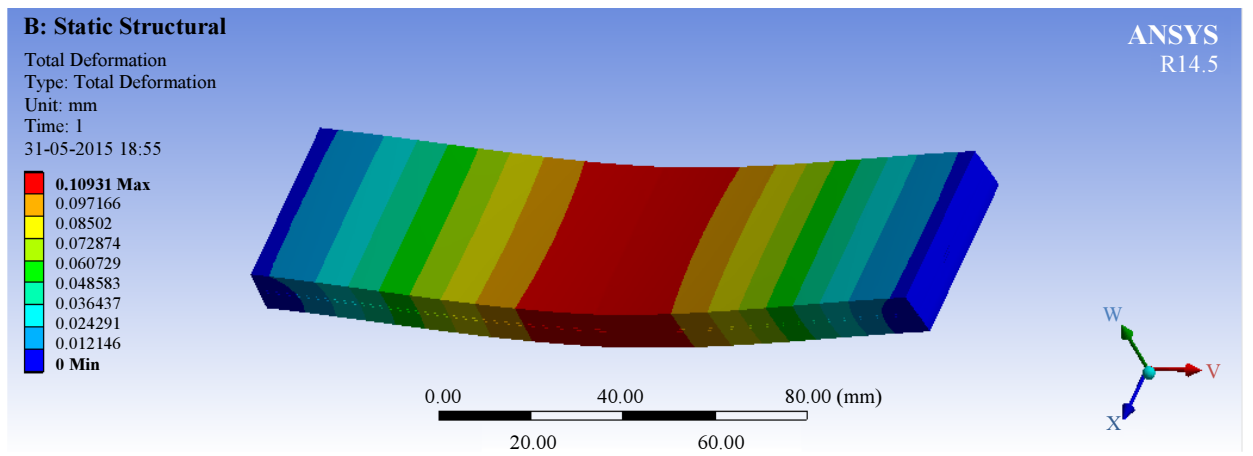

Fig. 13: Sample simulation output: Total deformation at $444 \mathrm{~N}$

Table 2: Results of regression analysis

Regression statistices

\begin{tabular}{ll}
\hline Multiple R & 0.873313 \\
R Square & 0.762676 \\
Adjusted R & \\
$\begin{array}{l}\text { Square } \\
\text { Standard }\end{array}$ & 0.747843 \\
Error & 50.63621 \\
Observations & 18
\end{tabular}

ANOVA

\begin{tabular}{|c|c|c|c|c|c|c|c|c|}
\hline & df & SS & MS & $\mathrm{F}$ & Significance $\mathrm{F}$ & & & \\
\hline Regression & 1 & 131837.9 & 131837.9 & 51.41831 & $2.23 \mathrm{E}-0$ & & & \\
\hline Residual & 16 & 41024.41 & 2564.026 & & & & & \\
\hline \multirow[t]{2}{*}{ Total } & 17 & $\begin{array}{c}172862.3 \\
\text { Standard }\end{array}$ & & & & & & \\
\hline & Cofficients & Error & t Stat & P-value & Lower 95\% & Upper 95\% & Lower $95.0 \%$ & Upper $95.0 \%$ \\
\hline Intercept & 163.8415 & 37.31897 & 4.390301 & 0.000456 & 84.72884 & 242.9542 & 84.72884 & 242.9542 \\
\hline $\mathrm{X}$ variable 1 & 160.0229 & 22.31635 & 7.170656 & $2.23 \mathrm{E}-06$ & 112.7143 & 207.3314 & 112.7143 & 207.3314 \\
\hline
\end{tabular}

Figure 12 and 13 show the sample simulation output reflecting the distribution of normal stress at $261.66 \mathrm{~N}$ and total deformation at $444 \mathrm{~N}$ throughout the LG sample respectively. The deflection at the center of the glass plate is $0.10931 \mathrm{~mm}$ (maximum) at a load of $444 \mathrm{~N}$ shown by the red colour and the deflection is $0 \mathrm{~mm}$ (least) at the edges shown by blue colour. The resulting values of deflection at first fracture of samples from experiments is $15-35 \%$ greater than that obtained by the software results, that can be considered as a good match for LG samples.
The variation of the normal stress is 7.16 to 14.20 . The variation in the normal stress and total deformation obtained by the simulation can be correlated.

Regression analysis is conducted for the validation and description of experimental results. Table 2 show the results obtained from the regression analysis. Table 2 shows that the $\mathrm{P}$ value of experimental results are much below 0.05 , so the error is within considerable limits. The noted residues reflect that data obtained is normally distributed and also qualifies the pencil thickness test on plotting. 


\section{Conclusion}

The present work includes five methods of treatment of LG samples. The method 2 and the method 5 have shown a good response as a considerable increment in bending strength of LG samples is noticed. The usability of the treatment methods could be increased if the method can be employed for operating part made by LG. The presented methods have the potential for modification to be used for the operating parts by LG. However, an additional approach, functional coating (highly hydrophobic coating) could be also a way to avoid sub-critical growth of cracks during aging, the stress corrosion and the stress concentration.

It was found that the treatment method significantly affects the strength of LG. The treatment method that includes $\mathrm{LiNO}_{3}$ instead of $\mathrm{KNO}_{3}$ during chemical treatment has shown better results due to a lower melting point of $\mathrm{LiNO}_{3}$. The microwave baking with the chemical treatment is also proved a potential method for improving the bending behaviour of LG. The fracture of LG during bending test shows that the crack is initially generated in the lower glass plate and not at the middle of the LG plate where actual loading was done but it generates near to that point. The surface composition and surface residual stresses may be evaluated in future work after each treatment method for better understanding of the mechanism of strengthening of LG. The crack patterns on two glass plates nearly overlap, the fracture in lower glass plate is followed by upper glass plate on increasing load in a quite similar manner. The regression analysis showed that the error during experimentation is within considerable limits. The higher average load is sustained by the LG sample but with larger average deformation. The results of present work reflected that the experimentation, analytical modeling, the FE simulation along with the use of the statistical techniques give conclusive results for designing the LG structures. It was also noticed that there is a strong requirement of the highly specialized numerical algorithms that can model the effect of treatment method on LG effectively. A numerical algorithm that can model multiple fractures experienced by the LG during bending and another loading effectively is also required for predicting the performance of LG during protective and structural applications. It would be interesting to know the effect of treatment on impact behavior of LG.

\section{Acknowledgments}

Present work is supported by Technical Education Quality Improvement Programme (TEQIP-II) of Motilal Nehru National Institute of Technology Allahabad, Allahabad (U.P.), India financially and also by Invertis University, Bareilly, (U.P.), India.

\section{Ethics}

This article is original and contains unpublished material. The corresponding author confirms that all of the other authors have read and approved the manuscript and there are no ethical issues involved.

\section{References}

ABAQUS, 2002. ABAQUS User Manual, Version 6.3, Hibbitt, Karlsson and Sorensen, Inc.

Aben, H. and C. Guillermet, 1993. Photoelasticity of Glass. 1st Edn., Springer-Verlag, Berlin.

Alhazov, D. and E. Zussman, 2012. Study of the energy absorption capabilities of laminated glass using carbon nanotubes. Composites Sci. Technol., 72: 681-687.

Araujo, R.J., S. Likitvanichkul, Y. Thibault and D.C. Allan, 2003. Ion exchange equilibria between glass and molten salts. J. Non-Cryst. Solids, 318: 262-267. DOI: 10.1016/S0022-3093(02)01888-4

Arrazola, P.J. and T. Özel, 2010. Investigations on the effects of friction modeling in finite element simulation of machining. Int. J. Mech. Sci., 52: 31-42. DOI: 10.1016/j.ijmecsci.2009.10.001

Asik, Z.M. and S. Tezcan, 2005. A mathematical model for the behavior of laminated glass beams. Comput. Struct., 83: 1742-1753. DOI: $10.1016 /$ j.compstruc.2005.02.020

Bao-Wei, F., K.Q. Zhu, Q. Shi, T. Sun and N.Y. Yuan et al., 2016a. Instantaneous stresses in the glass samples with different thicknesses. J. Non-Crystalline Solids, 437: 72-79. DOI: $10.1016 /$ j.jnoncrysol.2016.01.008

Bao-Wei, F., Z. Ke-Qian, S. Qiang, S. Tao and Y. NingYi et al., 2016b. Effect of glass thickness on temperature gradient and stress distribution during glass tempering. J. Non-Crystalline Solids, 437: 72-79. DOI: 10.1016/j.jnoncrysol.2016.01.008

Bedon, C., 2017. Structural glass systems under fire: Overview of design issues, experimental research and developments. Adv. Civil Eng. DOI: $10.1155 / 2017 / 2120570$

Behr, R.A., J. Minor and H. Norville, 1993. Structural behavior of architectural laminated glass. J. Struct. Eng., 119: 202-222. DOI: 10.1061/(ASCE)0733-9445(1993)119:1(202)

Belis, J., J. Depauw, D. Callewaert, D. Delince and R. Van, 2009. Failure mechanisms and residual capacity of annealed glass/SGP laminated beams at room temperature. Eng. Failure Anal., 16: 18661875. DOI: $10.1016 /$ j.engfailanal.2008.09.023

Biolzi, L., S. Cattaneo and G. Rosati, 2010. Progressive damage and fracture of laminated glass beams. Constr Build Mater., 24: 577-458. 
Boubakera, M.B., B.L. Correb and Y. Meshakaa, 2014. Finite element simulation of the slumping process of a glass plate using 3D generalized viscoelastic Maxwell model. J. Non Cryst. Solids, 405: 45-54. DOI: $10.1016 /$ j.jnoncrysol.2014.08.018

Brodland, G.W. and A.T. Dolovich, 2000. Curved-ray technique to measure the stress profile in tempered glass. Opt. Eng. Bellingham., 39-9: 2501-2505.

Calderone, I., P.S. Davies, S.J. Bennison, H. Xiaokun and L. Gang, 2009. Effective laminate thickness for the design of laminated glass. Glass Process. Days Tampere, Finland.

Cormier, L., D. Ghaleb, J.M. Delaye and G. Calas, 2000. Competition for charge compensation in borosilicate glasses: Wide-angle X-ray scattering and molecular dynamics calculations. Phys. Rev. B., 61: 14495-14499.

Deng, D. and H. Murakawa, 2006. Numerical simulation of temperature field and residual stress in multi-pass welds in stainless steel pipe and comparison with experimental measurements. J. Comp. Mater. Sci., 37: 269-277. DOI: 10.1016/j.commatsci.2005.07.007

Du, L.S. and J.F. Stebbins, 2005. Network connectivity in aluminoborosilicate glasses: A high-resolution 11B, 27Al and 17O NMR study. J. Non-Cryst. Solids, 351: 3508-3520.

Edel, M., 1997. The effect of temperature on the bending of laminated glass units. PhD thesis, Texas A\&M University.

Frischat, G.H., 1975. Ionic Diffusion in Oxide Glasses. Trans Tech Publications, Bay Village, pp: 181.

Fu, A.I. and J.C. Mauro, 2013. Mutual diffusivity, network dilation and salt bath poisoning effects in ionexchanged glass. J. Non-Cryst. Solids, 363: 199-204.

Galuppi, L. and G.R. Carfagni, 2014. Enhanced effective thickness of multi-layered laminated glass. Composites Part B, 64: 202-213.

Gilbert, C.J., V. Schroeder and R.O. Ritchie, 1999. Mechanisms for fracture and fatigue-crack propagation in a bulk metallic glass. Metallurgical Mater. Trans. A, 30: 1739-1753.

Greaves, G.N., 1998. Structural studies of the mixed alkali effect in disilicate glasses. Solids State Ionics, 105: 243-248.

Green, D.J., 2008. Recent developments in chemically strengthened glasses. Proceedings of the 64th Conference on Glass Problems: Ceramic Engineering and Science Proceedings, (CES' 08), John Wiley and Sons, Inc, pp: 253-266.

Gy, R., 2008. Ion exchange for glass strengthening. Mater. Sci. Eng. B, 149: 159-165. DOI: $10.1016 /$ j.mseb.2007.11.029

Hevesy, G.V., 1928. Elektrolytische Leitung in festen Körpern. Handbuch der Physik, Springer.
Hooper, J., 1973. On the bending of architectural laminated glass. Int. J. Mech. Sci., 15: 309-323.

Ivanov, I.V., 2006. Analysis, modelling and optimization of laminated glasses as plane beam. Int. J. Solids Struct., 43: 6887-6907.

Karlsson, S., B. Jonson and C. Stalhandske, 2010. The technology of chemical glass strengthening - a review. Glass Technol-Part A, 51: 41-54.

Koike, A., S. Akibaa, T. Sakagamia and K. Hayashia, 2012. Difference of cracking behavior due to Vickers indentation between physically and chemically tempered glasses. J. NonCryst. Solids, 24: 3438-3444. DOI: 10.1016/j.jnoncrysol.2012.02.020

Kolitsch, A. and E. Richter, 1980. Untersuchungen zur Ionenbeweglichkeit in einem NatriumKaliumAlumosilikatglass: Zur Einfluss Geringer Kationischer Verunreiningung in KNO3 auf den $\mathrm{K}+/ \mathrm{Na}+$ Ionenaustasch. Silikattechnik, 31: 247-249.

Kuske, A. and G. Robertson, 1974. Photoelastic Stress Analysis. 1st Edn., Wiley, London.

Li, H., P. He, J. Yu, L.J. Lee and A.Y. Yi, 2015. Localized rapid heating process for precision chalcogenide glass molding. Optics Lasers Eng., 73: 62-68.

Li, X., J. Lu and Z. Feng, 2013. Effect of hydrofluoric acid etching of glass on the performance of organicinorganic glass laminates. Composites: Part B, 52: 207-210.

Liu, M., R.S. Vallery, D.W. Gidley, M.E. Launey and J.J. Kruzic, 2009. Assessment of the fatigue transformation zone in bulk metallic glasses using positron annihilation spectroscopy. J. Applied Phys. DOI: $10.1063 / 1.3120784$

Loch, H. and D. Krause, 2002. Mathematical Simulation in Glass Technology. 1st Edn., Springer, Berlin.

Louter, C., J. Belis, F. Veer and J.P. Lebet, 2012. Durability of SG-laminated reinforced glass beams: Effects of temperature, thermal cycling, humidity and load-duration. Construct. Build. Mater., 27: 280-292. DOI: 10.1016/j.conbuildmat.2011.07.046

Maass, P., 1998. Towards a theory for the mixed alkali effect in glasses. J. Non-Cryst. Solids, 255: 35-46.

Mauro, J.C., 2011. Topological constraint theory of glass. Am. Ceram. Soc. Bull., 90: 31-37.

Mazzoldi, P., S. Carturan, A. Quaranta, C. Sada and V.M. Sglavo, 2013. Ion exchange process: History, evolution and applications. Riv Nuovo Cimento, 36: 397-460.

Min'ko, N.I. and N.M. Vladimir, 2013. Factors affecting the strength of the glass (Review). Middle-East J. Scientific Res., 18: 1616-1624.

Moynihan, G.T., A.J. Easteal and M.A. DeBolt, 1976. Dependence of the fictive temperature of glass on cooling rate. J. Am. Ceram. Soc., 59: 12-15. DOI: $10.1111 /$ j.1151-2916.1976.tb09376.x 
Narayanaswamy, O.S., 1971. A model of structural relaxation in glass. J. Am. Ceram. Soc., 54: 491-498.

Narayanaswamy, O.S., 1978. Stress and structural relaxation in tempering glass. J. Am. Ceram. Soc., 61: 146-152. DOI: 10.1111/j.1151-2916.1978.tb09259.x

Nielsen, J.H., J.F. Olesen and P.N. Poulsen, 2010. Finite element implementation of a glass tempering model in three dimensions. Comput. Struct., 88: 963-972. DOI: $10.1016 /$ j.compstruc. 2010.05 .004

Norville, H., K. King and J. Swoord, 1998. Behavior and strength of laminated glass. J. Eng. Mech., 124: 46-53. DOI: 10.1061/(ASCE)0733-9399(1998)124:1(46)

Pickett, A.K., T. Pyttel, F. Payen, F. Lauro and N. Petrinic et al., 2004. Failure prediction for advanced crashworthiness of transportation vehicles. Int. J. Impact Eng., 30: 853-872.

Saunders, A.E. and R.E. Kubichan, 1969. Strengthening glass by multiple alkali ion exchange. US patent 3433611 .

Serafinavičius, T., J.P. Lebet, C. Louter, T. Lenkimas and A. Kuranovas, 2013. Long-term laminated glass four point bending test with PVB, EVA and SG interlayers at different temperatures. Procedia Eng., 57: 996-1004.

Serafinaviciusa, T., J.P. Lebeta, C. Loutera, T. Lenkimasc and A. Kuranovas, 2013. Long-term laminated glass four point bending test with PVB, EVA and SG interlayers at different temperatures. Procedia Eng., 57: 1877-7058. DOI: 10.1016/j.proeng.2013.04.126

Seshadri, M., S.J. Bennison, A. Jagota and S. Saigal, 2002. Mechanical response of cracked laminated plates. Acta Materialia, 50: 4449-4693.

Sglavo, V.M., 2015. Chemical strengthening of soda lime silicate float glass: Effect of small differences in the KNO3 bath. Int. J. Applied Glas. Sci., 6: 72-82.

Sglavo, V.M., A. Quaranta, V. Allodi and G. Mariotto, 2014. Analysis of the surface structure of soda lime silicate glass after chemical strengthening in different $\mathrm{KNO}_{3}$ salt baths. J. Non-Cryst. Solids, 401: 105-109.

Shao, G.Z., Q.S. Wang and H. Zhao, 2014. Maximum temperature to withstand water film for tempered glass exposed to fire. Constr. Build. Mater., 57: 15-23. DOI: 10.1016/j.conbuildmat.2014.01.094

Sharma, S.K., A. Vedrtnam and S. Kumar, 2017. A review on acoustical properties measurement methods and a proposed novel method for acoustical characterization of laminated glass used in automotive applications. Int. J. Mechan. Product. Eng. Res. Dev., 7: 275-290. DOI: 10.24247/ijmperdaug201728

Shelestak, L.J.B., G.B. Goodwin, A. Mishra, J.M. Baldauff and J.S. Larry et al., 2005. Lithia-aluminasilica containing glass compositions and glasses suitable for chemical tempering and articles made using the chemically tempered glass.
Shelton and Mauro, 2010. Simple model for predicting the post-fracture Behavior of laminated Glass. Int. Conference, Parma, Italy.

Shepard, C.L., B.D. Cannon and M.A. Khaleel, 2003. Measurement of internal stress in glass articles. J. Am. Ceram. Soc., 86: 1353-1359. DOI: 10.1111/j.1151-2916.2003.tb03475.x

Smedskjaer, M.M., J.C. Mauro, J. Kjeldsen and Y. Yue, 2013. Microscopic origins of compositional trends in aluminosilicate glass properties. J. Am. Ceram. Soc., 96: 1436-1443.

Smedskjaer, M.M., J.C. Mauro, R.E. Youngman, C.L. Hogue and M. Potuzak et al., 2011. Topological principles of borosilicate glass chemistry. J. Phys. Chem. B, 115: 12930-12946.

Smedskjaer, M.M., J.C. Mauro, S. Sen and Y. Yue, 2010a. Quantitative design of glassy materials using temperature-dependent constraint theory. Chem. Mater., 22: 5358-5365.

Smedskjaer, M.M., J.C. Mauro and Y. Yue, 2010b. Prediction of glass hardness using temperaturedependent constraint theory. Phys. Rev. Lett.

DOI: 10.1103/PhysRevLett.105.115503

Soules, T.F., R.F. Busbey, S.M. Rekhson, A. Markovsky and M.A. Burke, 1987. Finite element calculation of stresses in glass parts undergoing viscous relaxation. J. Am. Ceram. Soc., 70: 90-95.

DOI: $10.1111 / \mathrm{j} .1151-2916.1987 . t b 04935 . \mathrm{x}$

Tool, A., 1976. Relation between inelastic deformability and thermal expansion of glass in its annealing range. J. Am. Ceram. Soc., 29: 240-253. DOI: $10.1111 / \mathrm{j} .1151-2916.1946 . t b 11592 . \mathrm{x}$

Tsujioka, N., Y. Saito, S. Tsutsui, Z.I. Maekawa and H.H.M. Kotaki et al., 2012. Properties of laminate composites reinforced with glass fabrics treated with sol-gel transition silicate gel. Composite Interfaces, 2: 105-115.

U.S. Patent Number 4591374, Apparatus for equalizing the temperature of conveyor rolls in a glasstempering furnace, O Y KYRO A B TAMGLASS.

U.S. Patent Number 4838915, Method for heating thickwalled glass tubes and apparatus therefore, Stiftelsen Institutet for Mikrovagsteknik Vid Tekniska Hogskolan.

U.S. Patent Number 5022908, Nippon Sheet Glass Co Ltd, apparatus for bending a glass sheet.

U.S. Patent Number 5057138, Tam glass Engineering Oy, Method and apparatus for preventing the arching of glass sheets in the roller-equipped furnace of a horizontal tempering plant.

U.S. Patent Number 5059233, Tam glass Engineering Oy, Method and apparatus for manufacturing a bent glass sheet.

U.S. Patent Number 5066320, Tam glass Engineering Oy, Method for bending complex shapes on a glass sheet. 
U.S. Patent Number 5078774, Tam glass Engineering Oy, Method and apparatus for heat-strengthening glass sheets.

U.S. Patent Number 5079931, Tam glass Oy, Bending or supporting mould for glass sheets.

U.S. Patent Number 5232482, Method for bending and tempering a glass sheet Tam glass Engineering Oy.

U.S. Patent Number 5306324, Method and apparatus for bending and tempering a glass sheet, Tam glass Engineering Oy.

U.S. Patent Number 5352263, Saint-Gobain Glass France SAS, Method and apparatus for bending glass plates in a horizontal position.

U.S. Patent Number 5368624, Method and apparatus for equalizing the temperature profile of glass sheets in a roller-equipped furnace included in a horizontal tempering plant, Tamglass Engineering Oy.

U.S. Patent Number 5591245, Tam glass Engineering Oy, Method and apparatus for developing an edge stress in a windshield bending furnace.

U.S. Patent Number 5656053, Method for heating and forming a glass sheet, Ford Global Technologies LLC Automotive Components Holdings LLC.

U.S. Patent Number 5743931, Pilkington United Kingdom Ltd, Glass sheet conveying and bending apparatus.

U.S. Patent Number 5755845, Method and apparatus for bending and tempering glass sheets, Flachglas Wernberg GmbH, Pilkington United Kingdom Ltd, Pilkington North America Inc.

U.S. Patent Number 5828042, Uniform heating apparatus for microwave oven and method thereof, LG Electronics Inc.

U.S. Patent Number 5858047, PPG Industries Inc, Method and apparatus of bending glass sheets

U.S. Patent Number 5882370, Pilkington United Kingdom Ltd, method of bending glass sheets.

U.S. Patent Number 6005230, Radiant heater for analytical laboratory use with precision energy control, non contamination exterior and uniform radiation footprint, WHITE R THOMAS JR.

US Patent Number 6408649 B1, Gyrotron Technology Inc, Method for the rapid thermal treatment of glass and glass-like materials using microwave radiation.

Varshneya, A.K. and I.M. Spinelli, 2009. High-strength, large-case-depth chemically strengthened lithium aluminosilicate glass. Am. Ceram. Soc. Bull., 88: 27-33.

Varshneya, A.K. and P.K. Kreski, 2012. The chemistry of chemical strengthening of glass. Ceramic Trans. DOI: $10.1002 / 9781118472590 . c h 12$

Varshneya, A.K., 2010a. The physics of chemical strengthening of glass: Room for a new view. J. Non-Cryst. Solids, 356: 2289-2294.

DOI: $10.1016 /$ j.jnoncrysol.2010.05.010
Varshneya, A.K., 2010b. Chemical strengthening of glass: Lessons learned and yet to be learned. Int. J. Applied Glas. Sci., 1: 131-142. DOI: $10.1111 /$ j.2041-1294.2010.00010.x

Varshneya, A.K., 2016. Mechanical model to simulate buildup and relaxation of stress during glass chemical strengthening. J. Non-Cryst. Solids, 433: 28-30. DOI: 10.1016/j.jnoncrysol.2015.11.006

Vedrtnam, A. and S.J. Pawar, 2013. Comparative evaluation and regression analysis of PVB, EVA and SG inter layered laminated glass hardness. Int. J. Eng. Res. Technol., 2: 16-28.

Vedrtnam, A. and S.J. Pawar, 2017a. Experimental and simulation studies on fracture of laminated glass having polyvinyl butyral and ethyl vinyl acetate interlayers of different critical thicknesses due to impact load. Glass Technol. Eur. J. Glass Sci. Technol. Part A, 58: 169-178. DOI: 10.13036/17533546.58.6.005

Vedrtnam, A. and S.J. Pawar, 2017b. Laminated plate theories and fracture of laminated glass plate- a review. Eng. Fracture Mechan., 186: 316-330. DOI: $10.1016 /$ j.engfracmech.2017.10.020

Vedrtnam, A. and S.J. Pawar, 2017c. Experimental and simulation studies on flexural strength of laminated glass using ring-on-ring and three-point bending test. Proc. IMechE Part C: J. Mechan. Eng. Sci. DOI: $10.1177 / 0954406217744815$

Vedrtnam, A. and S.J. Pawar, 2017d. Numerical analysis of impact fracture of laminated glass - a review. MOJ Civil Eng. DOI: 10.15406/mojce.2017.03.00086

Vedrtnam, A. and S.J. Pawar, 2017e. Experimental and simulation studies on fracture and adhesion test of laminated glass. Eng. Fract Mech. DOI: 10.1016/j.engfracmech. 2017.12.044

Vedrtnam, A. and S.J. Pawar, 2018. Experimental and simulation studies on fatigue behavior of laminated glass having polyvinyl butyral and ethyl vinyl acetate interlayers. Fatigue Fract Eng. Mater Struct. DOI: $10.1111 /$ ffe. 12788

Vedrtnam, A., 2018. Experimental and simulation studies on delamination strength of Laminated Glass composites having polyvinyl butyral and ethyl vinyl acetate inter-layers of different critical thicknesses. Defence Technol. DOI: 10.1016/j.dt.2018.02.002

$\mathrm{Wu}$, J. and J.F. Stebbins, 2010. Quench rate and temperature effects on boron coordination in aluminoborosilicate melts. J. Non-Cryst. Solids, 356: 2097-2108.

$\mathrm{Wu}$, J. and J.F. Stebbins, 2013. Temperature and modifier cation field strength effects on aluminoborosilicate glass network structure. J. NonCryst. Solids, 362: 73-81.

Xiangchen, Z., H. Ouli, X. Cengzuo and Z. Yinghuan, 1986. The effect of impurity ions in molten salt $\mathrm{KNO}_{3}$ on ion-exchange and strengthening of glass. J. NonCryst. Solids, 80: 313-318.

DOI: 10.1016/0022-3093(86)90412-6 
Zhang, X. and C. Bedon, 2017. Vulnerability and protection of glass windows and facades under blast: Experiments, methods and current trends. Int. J. Struct. Glass Adv. Mater. Res., 1: 10-23. DOI: $10.3844 /$ sgamrsp.2017.10.23

Zhang, X.H., H. Hao and Z.Q. Wang, 2014. Experimental investigation of monolithic tempered glass fragment characteristics subjected to blast loads. Eng. Struct., 75: 259-275. DOI: 10.1016/j.engstruct.2014.06.014
Zheng, Q., M. Potuzak, J.C. Mauro, M.M. Smedskjaer and R.E. Youngman et al., 2012a. Composition-structureproperty relationships in boroaluminosilicate glasses. J. Non-Cryst. Solids, 358: 993-1002.

Zheng, Q.J., R.E. Youngman, C.L. Hogue, J.C. Mauro and M. Potuzak et al., 2012b. Structure of Boroaluminosilicate Glasses: Impact of $\left[\mathrm{Al}_{2} \mathrm{O}_{3}\right] /\left[\mathrm{SiO}_{2}\right]$ ratio on the structural role of sodium. Phys. Rev. B. DOI: 10.1103/PhysRevB.86.054203 